\title{
First case of Plasmodium knowlesi infection in a Japanese traveller returning from Malaysia
}

\author{
Ryutaro Tanizaki ${ }^{1 *}$, Mugen Ujiie', Yasuyuki Kato ${ }^{1}$, Moritoshi Iwagami ${ }^{2}$, Aki Hashimoto $^{1}$, Satoshi Kutsuna', \\ Nozomi Takeshita ${ }^{1}$, Kayoko Hayakawa ${ }^{1}$, Shuzo Kanagawa', Shigeyuki Kano ${ }^{2}$ and Norio Ohmagari ${ }^{1}$
}

\begin{abstract}
This is the first case of Plasmodium knowlesi infection in a Japanese traveller returning from Malaysia. In September 2012, a previously healthy 35-year-old Japanese man presented to National Center for Global Health and Medicine in Tokyo with a two-day history of daily fever, mild headaches and mild arthralgia. Malaria parasites were found in the Giemsa-stained thin blood smear, which showed band forms similar to Plasmodium malariae. Although a nested PCR showed the amplification of the primer of Plasmodium vivax and Plasmodium knowlesi, he was finally diagnosed with $P$. knowlesi mono-infection by DNA sequencing. He was treated with mefloquine, and recovered without any complications. DNA sequencing of the PCR products is indispensable to confirm P. knowlesi infection, however there is limited access to DNA sequencing procedures in endemic areas. The extent of $P$. knowlesi transmission in Asia has not been clearly defined. There is limited availability of diagnostic tests and routine surveillance system for reporting an accurate diagnosis in the Asian endemic regions. Thus, reporting accurately diagnosed cases of $P$. knowlesi infection in travellers would be important for assessing the true nature of this emerging human infection.
\end{abstract}

Keywords: Plasmodium knowlesi, Malaria, Traveller, Imported, Mefloquine, Japan

\section{Background}

The first naturally acquired zoonotic infection with Plasmodium knowlesi in a human was reported in 1965 [1]; thereafter, no such infections were reported for almost 40 years. In 2004, however, Singh et al. [2] reported that natural $P$. knowlesi infections in humans were common parasite species in Malaysia. Cox-Singh et al. [3] subsequently described that $P$. knowlesi infections in humans were observed throughout wide areas of Southeast Asia, including Thailand, Myanmar, the Philippines, Singapore and Indonesia. Additionally, 12 cases of $P$. knowlesi infection in travellers have been reported from nonmalaria endemic countries thus far [1,4-14]. Here, this is the first confirmed case of $P$. knowlesi infection in a Japanese traveller.

\footnotetext{
*Correspondence: k_taro023@yahoo.co.jp

1 Disease Control and Prevention Center, National Center for Global Health and Medicine, 1-21-1 Toyama, Shinjuku-ku, Tokyo 162-8655, Japan Full list of author information is available at the end of the article
}

\section{Case presentation}

In September 2012, a previously healthy 35-year-old Japanese man presented to the travel clinic in National Center for Global Health and Medicine (NCGM), Tokyo with a two-day history of daily fever, mild headache, and mild arthralgia. He had visited Malaysia for entomological and botanical field investigations over a twomonth period and had stayed at Temengor (four weeks), Johor (two weeks), and Kuala Lumpur (two weeks). While in Temengor, he stayed in a tent located near a forest and had not used any malaria prevention measures, such as bed nets, mosquito repellents or chemoprophylaxis. During his stay, he was bitten by mosquitoes and saw some wild monkeys. He had no health problems and was in a good physical condition until he experienced a sudden high fever $\left(39.0^{\circ} \mathrm{C}\right.$ axillary temperature) the day after his return to Japan. He had fever spikes of $>38.0^{\circ} \mathrm{C}$ in a 24-hour period. On the third day of his illness, he was admitted to NCGM. On admission his body temperature was $37.0^{\circ} \mathrm{C}$, with blood pressure of $111 / 80 \mathrm{mmHg}$, pulse rate of 115 beats per minute, respiration rate of 16 per minute, and oxygen

\section{Biomed Central}

(c) 2013 Tanizaki et al.; licensee BioMed Central Ltd. This is an Open Access article distributed under the terms of the Creative Commons Attribution License (http://creativecommons.org/licenses/by/2.0), which permits unrestricted use, distribution, and reproduction in any medium, provided the original work is properly cited. 
saturation of 99\% (room air). Physical examination revealed mild splenomegaly and left upper abdominal pain. Laboratory investigations showed thrombocytopenia $\left(47 \times 10^{3}\right.$ cells $/ \mathrm{mm}^{3}$, reference range $150-350$ cells/ $\mathrm{mm}^{3}$ ), elevated liver enzymes (serum aspartate aminotransferase $49 \mathrm{U} / \mathrm{L}$, reference range $13-33 \mathrm{U} / \mathrm{L}$; alanine aminotransferase $41 \mathrm{U} / \mathrm{L}$, reference range 8-42 U/L; alkaline phosphatase $428 \mathrm{U} / \mathrm{L}$, reference range 115-359 $\mathrm{U} / \mathrm{L}$; and total bilirubin $1.1 \mathrm{mg} / \mathrm{dl}$, reference range 0.3 $1.2 \mathrm{mg} / \mathrm{dl})$, a high C-reactive protein level $(11.59 \mathrm{mg} / \mathrm{dl}$, reference range $0-0.3 \mathrm{mg} / \mathrm{dl}$ ), no anaemia (haemoglobin $17.3 \mathrm{~g} / \mathrm{dl}$, reference range $13.5-17.0 \mathrm{~g} / \mathrm{dl}$ ), and a normal leukocyte count $\left(3,860\right.$ cells $/ \mathrm{mm}^{3}$, reference range 3,500 $8,500 / \mathrm{mm}^{3}$ ). The patient's free blood glucose levels and renal function were normal. Although rapid diagnostic tests (BinaxNOW Malaria ${ }^{\circledR}$; Alere, Inc, Scarborough, USA) for the Plasmodium falciparum histidine-rich protein 2 and pan-malarial aldolase were negative, malaria parasites were identified in the patient's Giemsa-stained thin blood smear from which a parasitaemia of $0.2 \%$ $(10,120$ parasites/ $\mu \mathrm{l})$ was calculated. The morphological features of the parasites comprised band forms, which are similar to those characteristics of Plasmodium malariae, and heavily pigmented schizonts inside nonenlarged erythrocytes (Figure 1). To make a definitive diagnosis, two partial gene regions (the small subunit rRNA from nuclear DNA and cytochrome $b$ from mitochondrial DNA) from five malaria parasite species were tried to be amplified by nested PCR, using respective primer sets for P. falciparum, Plasmodium vivax, Plasmodium ovale, $P$. malariae and $P$. knowlesi. The positive result was obtained by the primer sets of $P$. knowlesi and $P$. vivax in the amplification of the partial small subunit rRNA gene. However, in the amplification of the partial cytochrome $b$ gene, the positive result was obtained by the P. knowlesi primer sets (Figure 2). The sequences of the PCR products were determined using an ABI 3130xl Genetic Analyzer (Applied Biosystems, CA, USA) after TA cloning. From this sequence analysis, the patient was confirmed that even the PCR product amplified by the $P$. vivax primer sets for the partial small subunit rRNA gene was proved to be the DNA of P. knowlesi. He was treated with mefloquine $(1,500 \mathrm{mg}$ base), then was repeated the microscopic screening for parasites every

(A) Before administration of mefloquine

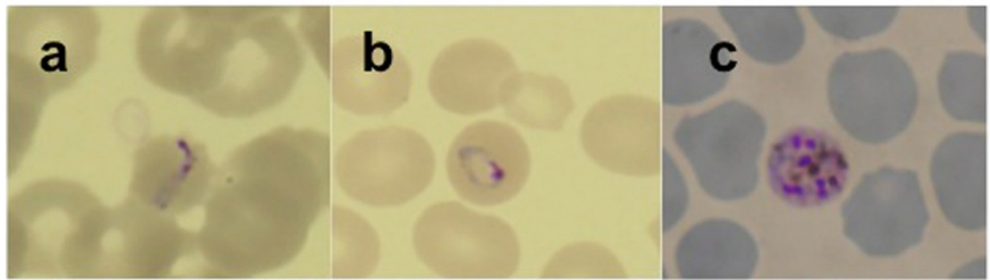

(B) 4 hours after administration of mefloquine

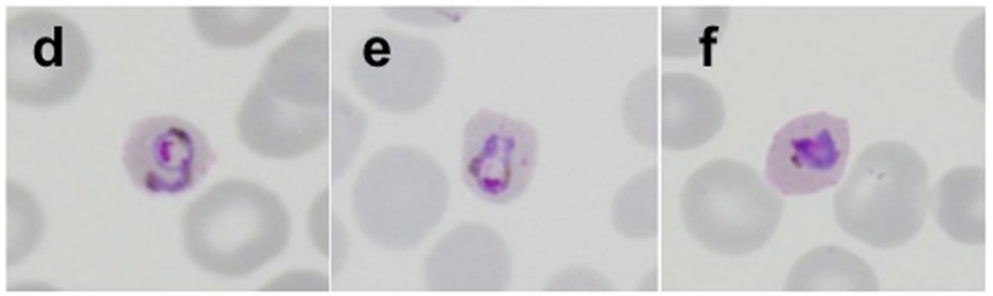

(C) 16 hours after administration of mefloquine

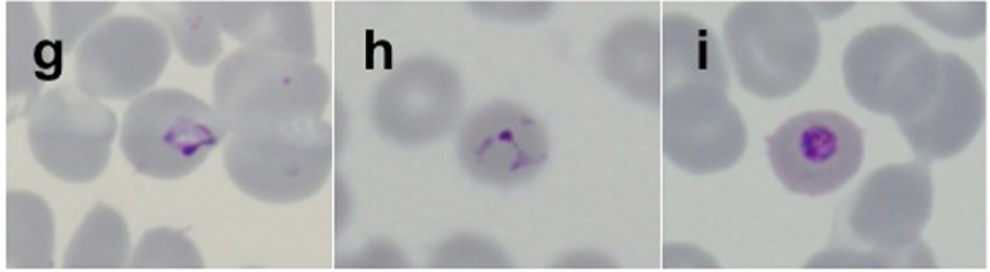

Figure 1 Microscopic analysis of Giemsa-stained thin blood-smears from a patient infected with Plasmodium knowlesi malaria parasites. The blood smears were taken before $(\mathbf{A})$, four hours after (B), and 16 hours after treatment $(\mathbf{C})$, respectively. A) Before mefloquine treatment the following blood-stage parasites were observed: a) band form, b) ring form, and c) schizont. B, C) Post-mefloquine treatment (B, C), the ring forms $(\mathrm{d}, \mathrm{e}, \mathrm{g}, \mathrm{h})$ and trophozoites $(\mathrm{f}$, i) gradually changed into irregular forms. The parasitaemias calculated from slides $\mathbf{A}$, $\mathbf{B}$, and $\mathbf{C}$ were $0.2 \%, 0.05 \%$, and $0.013 \%$, respectively. 


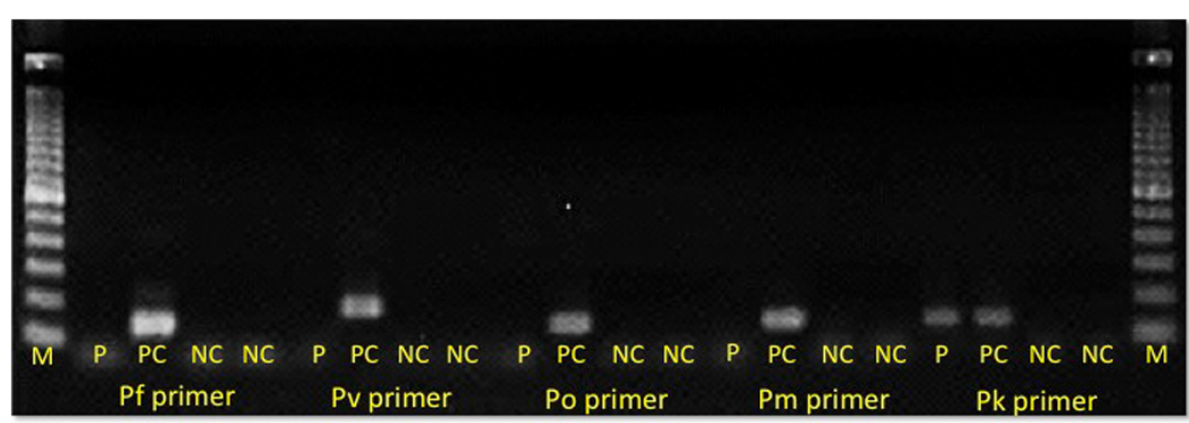

Figure 2 Nested PCR results from the inner primers. The region amplified was a partial sequence of the cytochrome $b$ gene (mitochondrial DNA) from different malaria parasite species ( 130-180 bp). M: DNA size marker, P: patient, Pf: Plasmodium falciparum, Pv: Plasmodium vivax, Po: Plasmodium ovale, Pm: Plasmodium malariae and, Pk: Plasmodium knowlesi. PC: positive control, NC: negative control. Forward primers for the outer PCR and the inner PCR were the same as those reported by Putaporntip et al. [15]. The sequences of the reverse primers used for the outer PCR and the inner PCR are as follows: PCBR-ed (5'-ACATAATTATAACCTTACGGTCTG-3'), PfCBR-ed (5'-GATTTGTTCCGCTCAATAC-3'), PVCBR-ed (5'-CTG TATTGTTCTGCTCAA-3'), PoCBR-ed (5'-CTGTATTGTTCTGCTCAT-3'), PmCBR-ed (5'-CTGTATTGTTCTGCACAG-3'), PkCBR-ed (5'-GTATTGTTCTAATCAGTGTA-3'). Nested PCR primers for the small-subunit rRNA from parasite nuclear DNA were the same as those reported by Kimura et al. [16] (gel not shown). The inner PCR primer (reverse) used to amplify P. knowlesi DNA (SS-rRNA-Pk-R) had the following sequence: 5'-AAGAGTTCTAATCTCCGGAGAGAAAAG-3'. DNA sequences of the partial cytochrome $b$ gene and SSU rRNA gene were deposited in the DNA Data Bank of Japan (DDBJ). The DDBJ accession numbers of the DNA sequences of the partial cytochrome $b$ gene and SSU rRNA gene were AB787188 and AB787187, respectively. A positive band for the patient's blood sample with $P$. knowlesi primer sets was shown.

12 hours for confirming parasite disappeared. The clinical course of the mefloquine treatment in this patient was as follows: the initial band-form and schizont-stage parasites seen in the Giemsa-stained blood smears disappeared six hours after administration of the drug and, gradually, the shape of the ring-form parasites became more irregular over time (Figure 1). The parasites disappeared completely from the blood 40 hours later, and the patient's fever resolved 28 hours after mefloquine administration. The patient was discharged from hospital on the seventh day post-admission, without any complications. No relapses or any other health problems were observed over a five-month period.

\section{Conclusions}

Most $P$. knowlesi infections are reported in the rural jungle areas of the Malaysia peninsular and in Borneo (Sabah [17] and Sarawak [2] province) where both of the infectious hosts (macaque and leaf monkeys) and vectors (Anopheles mosquitoes) predominantly exist. The patient in this case was probably infected with $P$. knowlesi in the Temengor jungle area as he had not entered any other areas of jungle for four weeks before returning to Japan. Interestingly, the incubation period in this patient was probably over four weeks, which is longer than the nine to 12 day incubation period reported for P. knowlesi [18]. This finding is consistent with a case report for a different traveller who also experienced a long incubation period ( $>17$ days) [13]. Clinical data for P. knowlesi infection in travellers are limited; therefore, more data are needed to determine the correct incubation period for P. knowlesi.
No cases of treatment failure have been reported in travellers treated with anti-malarial drugs such as quinine [4], doxycycline [4], mefloquine [8], atovaquone/proguanil [5,10,14], and artemether/lumefantrine [12]. In the present case, mefloquine enabled the patient to recover without any complications. Chloroquine has been usually used for uncomplicated $P$. knowlesi infection [19]; however, in recent years, a prospective comparative study suggested that early intravenous artemisinin treatment improved the prognosis in severe cases of $P$. knowlesi infection [17]. The major risk factors of increasing severity are associated with a high parasitaemia $[17,20]$ and thrombocytopenia [20]. The risk factors of severity in $P$. knowlesi infection should be evaluated appropriately, and if necessary, should be considered the intravenous artemisinin treatment as other malaria parasite species [21].

Microscopic examination of Giemsa-stained blood smears is the gold standard for differentiating Plasmodium species; however, differentiating $P$. knowlesi from other malaria species is very difficult because $P$. knowlesi band forms and schizonts of mature trophozoites in P. knowlesi are similar to those of $P$. malariae, while the ring forms of $P$. knowlesi early trophozoites are similar to those of $P$. falciparum $[2,17,18]$. This patient was initially suspected of contracting $P$. malariae after observing his Giemsastained thin blood smear (Figure 1). Although PCR is required to obtain a definitive diagnosis, the spurious amplification of a $P$. vivax gene using $P$. knowlesi-specific primers has been reported [22]. In the present study, on the other hand, a $P$. knowlesi gene was amplified using $P$. vivax-specific primers [16]. These spurious amplifications were observed when the target gene of PCR was the small subunit rRNA gene [22] because of the similarity between 
the DNA sequences of $P$. knowlesi and $P$. vivax. Thus, a caution is needed for using this gene to differentiate malaria species by PCR. Indeed, some cases of $P$. knowlesi infection in travellers have been initially diagnosed as $P$. ovale [4] or P. vivax [13] by nested PCR; however, these were later confirmed as $P$. knowlesi by DNA sequencing. Therefore, DNA sequencing is indispensable for final confirmation of $P$. knowlesi infection.

There is limited access to DNA sequencing procedures for identifying P. knowlesi in endemic areas. Hence, accurate reporting of clinical and epidemiological data should contribute to better understanding of the clinical features of $P$. knowlesi infection, as well as the true incidence of the disease. Close monitoring of febrile travellers returning from $P$. knowlesi-endemic areas and complete travel histories (including exposure to areas with wild monkeys) should prompt suspicion of $P$. knowlesi infection [17] and a move towards further diagnostic tests. Additionally, greater awareness of the risk of the emerging $P$. knowlesi problem in travellers is necessary among health care workers in non-endemic countries. Thus, reporting accurately diagnosed cases of $P$. knowlesi infection in travellers would be important for assessing the true nature of this emerging human infection.

\section{Consent}

Oral informed consent was obtained from the patient for publication of this case report and any accompanying images after explanation of the report objectives.

\section{Competing interests}

All authors declare that they have no competing interests.

\section{Authors' contributions}

RT, MU, MI, YK, and S Kano wrote the paper. RT, MU, AH, S Kutsuna, NT, KH, S Kanagawa and NO were the physicians responsible for the patient. MU, YK, MI, S Kano supervised molecular characterization of parasite, conceived the study, its design and coordination. MI and S Kano performed microscopic examination of the blood smears, DNA analyse and drafted the manuscript. All authors have read and approved the final manuscript.

\section{Acknowledgements}

The authors are gratefully acknowledge Kanako Komaki-Yasuda, Kazuhiko Yano and Shungo Kano at the Department of Tropical Medicine and Malaria, Research Institute, National Center for Global Health and Medicine, Japan for their technical expertise in microscopy, and Satoru Kawai at the Center for Tropical Medicine and Parasitology, Dokkyo Medical University, Japan for technical advice and for designing PCR primers for diagnosis of P. knowlesi. This work was partly supported by funding from the Research on Emerging and Re-emerging Infectious Diseases by the Ministry of Health, Labour, and Welfare, Japan (H24-shinkou-ippan-013).

\section{Author details}

${ }^{1}$ Disease Control and Prevention Center, National Center for Global Health and Medicine, 1-21-1 Toyama, Shinjuku-ku, Tokyo 162-8655, Japan. ${ }^{2}$ Department of Tropical Medicine and Malaria, Research Institute, National Center for Global Health and Medicine, 1-21-1 Toyama, Shinjuku-ku, Tokyo 162-8655, Japan.

\section{References}

1. Chin W, Contacos PG, Coatney GR, Kimball HR: A naturally acquired quotidiantype malaria in man transferable to monkeys. Science 1965, 149:865.

2. Singh B, Kim Sung L, Matusop A, Radhakrishnan A, Shamsul SS, Cox-Singh J, Conway DJ, Thomas A: A large focus of naturally acquired Plasmodium knowlesi infections in human beings. Lancet 2004, 363:1017-1024.

3. Cox-Singh J, Singh B: Knowlesi malaria: newly emergent and of public health importance? Trends Parasitol 2008, 24:406-410.

4. Kantele A, Marti H, Felger I, Muller D, Jokiranta TS: Monkey malaria in a European traveller returning from Malaysia. Emerg Infect Dis 2008, 14:1434-1436.

5. Centers for Disease Control and Prevention (CDC): Simian malaria in a U.S. traveller-New York, 2008. MMWR Morb Mortal Wkly Rep 2009, 58:229-232.

6. Kuo M-C, Chiang T-Y, Chan C-W, Tsai W-S, Ji D-D: A case report of simian malaria, Plasmodium knowlesi, in a Taiwanese traveller from Plawan island, the Philippines. Taiwan Epidemiol Bulletin 2009, 25:178-191.

7. van Hellemond JJ, Rutten M, Koelewijn R, Zeeman AM, Verweij JJ, Wismans PJ, Kocken $\mathrm{CH}$, van Genderen PJ: Human Plasmodium knowlesi infection detected by rapid diagnostic tests for malaria. Emerg Infect Dis 2009, 15:1478-1480.

8. Bronner U, Divis PC, Färnert A, Singh B: Swedish traveller with Plasmodium knowlesi malaria after visiting Malaysian Borneo. Malar J 2009, 8:15.

9. Ta T, Salas A, Ali-Tammam M, Martínez Mdel C, Lanza M, Arroyo E, Rubio JM: First case of detection of Plasmodium knowlesi in Spain by real time PCR in a traveller from Southeast Asia. Malar J 2010, 9:219.

10. Figtree M, Lee R, Bain L, Kennedy T, Mackertich S, Urban M, Cheng Q, Hudson BJ: Plasmodium knowlesi in human, Indonesian Borneo. Emerg Infect Dis 2010, 16:672-674.

11. van Hellemond JJ, van Genderen PJ: Monkey malaria in a traveller from Malaysia. Ned Tijdschr Geneeskd 2010, 154:A1353.

12. Hoosen A, Shaw MT: Plasmodium knowlesi in a traveller returning to New Zealand. Travel Med Infect Dis 2011, 9:144-148.

13. Berry A, Iriart X, Wilhelm N, Valentin A, Cassaing S, Witkowski B, Benoit-Vical S, Olangnier D, Fillaux J, Sire S, Le Coustumier A, Magnaval JF: Imported Plasmodium knowlesi malaria in a French tourist returning from Thailand. Am J Trop Med Hyg 2011, 84:535-538.

14. Link L, Bart A, Verhaar N, van Gool T, Pronk M, Scharnhost V: Molecular detection of Plasmodium knowlesi in a Dutch traveller by real-time PCR. J Clin Microbiol 2012, 50:2523-2524.

15. Putaporntip C, Buppan $P$, Jongwutiwes S: Improved performance with saliva and urine as alternative DNA sources for malaria diagnosis by mitochondrial DNA-based PCR assays. Clin Microbiol Infect 2011, 17:1484-1491.

16. Kimura M, Kaneko O, Liu Q, Zhou M, Kawamoto F, Wataya Y, Otani S, Yamaguchi $Y$, Tanabe $K$ : Identification of the four species of human malaria parasites by nested PCR that targets variant sequences in the small subunit rRNA gene. Parasitol Int 1997, 46:91-95.

17. Barber BE, William T, Grigg MJ, Menon J, Auburn S, Marfurt J, Anstey NM Yeo TW: A prospective comparative study of knowlesi, falciparum and vivax malaria in Sabah, Malaysia: high proportion with severe disease from Plasmodium knowlesi and $P$. vivax but no mortality with early referral and artesunate therapy. Clin Infect Dis 2013, 56:383-397.

18. Coatney RG, Collins WE, Warren MW: The primate malarias Washington. US Government Printing Office 1971, 26:317-333.

19. Daneshvar C, Davis TM, Cox-Singh J, Rafa'ee MZ, Zakaria SK, Divis PC, Singh B: Clinical and parasitological response to oral chloroquine and primaquine in uncomplicated human Plasmodium knowlesi infections. Malar J 2010, 9:238.

20. Willmann M, Ahmed A, Siner A, Wong IT, Woon LC, Singh B, Krishna S, CoxSingh J: Laboratory markers of disease severity in Plasmodium knowlesi infection: a case control study. Malar J 2012, 11:363.

21. WHO: Guidelines for the treatment of malaria. 2nd edition. Geneva: World Health Organization; 2010.

22. Imwong M, Tanomsing N, Pukrittayakamee S, Day NP, White NJ, Snounou G Spurious amplification of a Plasmodium vivax small-subunit RNA gene by use of primers currently used to detect P. knowlesi. J Clin Microbiol 2009, 47:4173-4175.

doi:10.1186/1475-2875-12-128

Cite this article as: Tanizaki et al:: First case of Plasmodium knowlesi infection in a Japanese traveller returning from Malaysia. Malaria Journal $201312: 128$ 